\title{
Based on the Cross-strait Exchanges, The Yangqin Development and Gradual Change of Taiwanese Gezai Opera (Xiang Opera) in Fujian and Taiwan
}

\author{
Chin-niang Chan ${ }^{1}$ \\ Fujian Minnan Normal University of Art College \\ About the author: Dr. Zhan jinniang (1967 -), female, associate professor, School of art, Fujian Minnan Normal \\ University. \\ Fund Project: This paper is the general project of Fujian Social Science Planning Project Art Fund in 2019: \\ Fujian Taiwan Gezai Opera (Xiang Opera) \\ Phased achievements of Yangqin Development Research (Project No.: fj2019b029).
}

\begin{abstract}
Gezi Opera is the only kind of opera that uses Yangqin as the accompaniment instrument in the social and cultural inheritance and reproduction of immigrants from Fujian and Taiwan. In terms of cultural communication, Gezi Opera and Xiang opera Yangqin are regarded as sister flowers. Although they come down in one continuous line and share the same root, with the confrontation between the two sides in 1949 and the transfer of regional time and space, they interrupted each other's exchanges and took their own development in the historical context and social structure. From the perspective of culture and civilization, this paper examines the shape variation of Yangqin as an accompaniment instrument of Gezi Opera after the reform and opening up on both sides of the Strait in 1987. Thus, when tradition meets modernity, even if there is a century of culture, it is hard to escape the bad luck of abandoning it like shoes.
\end{abstract}

Keywords: traditional dulcimer; Taiwanese opera; Xiang opera; twelvetone equal temperament

DOI: $10.7176 /$ RHSS/11-22-02

Publication date: November $30^{\text {th }} 2021$

\section{Preface}

Yangqin was introduced into China in the late Ming Dynasty and early Qing Dynasty. Its novel style and sonorous timbre spread everywhere with the flow of musicians. It is not only used for folk God welcoming games, year-old festivals, literati Yashi's self entertainment or music club pomp, but also the most eye-catching musical instrument in private collection, official merchants and children's Pavilion music club pomp.

The reproduction and reorganization of immigrant culture and the production of new culture. According to the research data of $\mathrm{Xu}$ Yaxiang's "Chinese theatrical troupes in Taiwan during the Japanese rule" and Wu Chunhui's "an overview of the amateur troupes", although the two sides were politically isolated from each other from 1899 to 1936, the cultural exchanges between the two sides were not interrupted. In particular, the largescale performance mode of mainland theatrical troupes across Taiwan was more sensitive to the aesthetic view of Taiwanese people's opera music The performance skills and musical instrument timbre of the musicians in the backstage of the troupe play a role in enriching and improving. ${ }^{1}$

In this way, Yangqin gradually revealed its dawn in the accompaniment performance of musicians from mainland troupes in Taiwan. On the exchange of theatrical troupes between the two sides of the Strait, take "the development history of Taipei Beiguan art" as an example - Field records ${ }^{2}$. Lin Heyi and Cai Xinxin's light, shadow, people and History: old photos of Gezi present the most wonderful scenes of opera performers and musicians in the form of historical relics.

In addition, field visits are added to illustrate the emergence and dissemination of ballads with the experience of musicians; In particular, the development of [National Day tune] introduced through Xiamen and [Duma tune] introduced in 1948 by the anti establishment capital horse troupe of Nanjing in Gezi Opera Troupe and [seven character tune] laid the foundation for the development of Yangqin into the Opera Troupe and became the main position of the five main musical instruments of Gezi Opera. ${ }^{3}$ From Lin Heyi's and Xu meihui's "refining - Chen Yu's performance style and his era", Huang Shiqiao's "the prosperity of Dadaocheng" and other focused discussions, it is known that after Yangqin entered Fujian from the Silk Road into Taiwan, it has never been suppressed or excluded despite the changes of times. ${ }^{4}$

On the contrary, because of the historical light and shadow of the Western multi-cultural stack, under the rule of different nationalities, it stands out from the era context and music landscape of the coexistence of "East / West", "tradition / modern" and "conservative / innovative", and preserves the music development of the compatibility of Chinese traditional pentatonic scale and Western harmony.

With the development and changes of politics, economy, society and culture on both sides of the Strait, there are music scores examples from different times. According to the love of the public and the status of the back stage 
musician of the troupe, they take root and thrive, and gradually shape into the artistic ecology and aesthetic characteristics of Gezai Opera Yangqin, which has become an indispensable main musical instrument in the musical style of Taiwan opera.

\section{Dulcimer and accompaniment ballads on the maritime Silk Road}

Yangqin is a worldwide stringed instrument. It was introduced into China from the south to the north with the trade between land and Sea Silk Road in the late Ming Dynasty and early Qing Dynasty. For all kinds of folk music, rap and opera music, it absorbs as accompaniment instruments. Fujian is located in the southeast coast. Since the Tang and Five Dynasties, overseas trade has been frequent and the urban economy has been prosperous,Promote the prosperity of music, dance, acrobatics and drama.

In order to prevent Japanese pirates and bandits from repeatedly invading and causing trouble along China's coast, the Ming Dynasty implemented the sea ban policy. In the first year of Longqing (1567), the opening of the sea ban was announced and announced. Only Zhangzhou Yuegang was allowed to be built, and the system of "ship leading" was implemented to allow people to go to sea. The legal identity of private people was mainly to expand international trade and open the overseas trade of barter, which not only replenished tens of millions of silver for the national treasury that could not make ends meet, but also promoted the activity of domestic commodity economy.

Compared with the 200 year sea ban of the Ming Dynasty, the Qing government opened overseas trade doors and attracted a large number of foreign businessmen to engage in overseas trade. The policy of locking up the country after 200 years of sea ban. In the 24th year of Kangxi of the Qing Dynasty (1685), the Imperial Court opened the sea ban to foreign countries. A large number of foreign trade businessmen and missionaries landed in China from Fuzhou, Quanzhou, Guangzhou, Yuegang and Yangzhou along the Southeast coast of Fujian. The booming sea trade was the highest in all dynasties.

Taiwan is located on the East Bank of Fujian and faces each other across the Taiwan Strait. Due to its geographical location, the vigorous development of the maritime Silk Road in the second half of the 17th century made the Han people immigrate to Sri Lanka. In addition to the customs and habits of the Gaoshan aborigines, most of the immigrants came from Zhangquan, Fujian and Guangdong. Their daily materials and customs are no different from their original life. Therefore, the North-South tube Fulao ballads, Hakka music and local opera music are not only entertainment at ordinary times, but also indispensable rituals for folk festivals, Temple sacrifices and people's weddings and funerals in belief culture. They maintain the reproduction of Han culture and the reorganization and regeneration of immigrant culture.

The "Songs" brought by immigrant culture reflect immigrants' yearning for their hometown and expectations for a new life in the future. Groups of people praise and criticize each other in the way of singing. You come and go, which became the leisure and entertainment of busy farming and leisure at that time, and the children of rich families sang in the song hall. Lu v. the "song hall" mentioned in the "history of Taiwan film" belongs to the children's hall. Most of the biggest sponsors behind the scenes are suburban businessmen from both sides of the Strait. As long as it is an important activity of the business firm, the children will try their best to help. The language of Southern Fujian, similar ballads, poetry and music, beautiful characters and singing in island language. ${ }^{5}$

Therefore, the "competition" between the pavilion and the pavilion has become one of the most wonderful performance activities among commercial banks to show their financial resources and competition. The number of participants, innovative stages, costumes and backcourt musical instruments are extremely competitive. Yangqin was a rare and expensive instrument at that time. Naturally, it was absorbed into the troupe and became a financial symbol in the competition activities of the pavilion. With the enthusiastic participation of the audience and the exquisite skills of the musicians, local Gezi pavilions were set up one after another. The Yangqin consumed by the upper class was absorbed into the accompaniment instrument of the pavilion, highlighting the identity and status of the pavilion. ${ }^{6}$

From the stage of leisure and entertainment of the mass "Gezi" in the Qing Dynasty to the commercial "selling medicine" and the rap of "landing sweeping", it absorbed the nutrients of performance forms such as car drum array, Siping opera, Tea Picking Opera and random play, and added the "Ballad into the play" of hand and foot dance, which showed the footprint of the existence of Yangqin. It is adapted from the development of folk legends, and gradually forms the form of songs in series and compiled into complete stories and performances. Depending on folk beliefs and age festivals, Yangqin connects the development of the mother culture of the motherland in the Qing Dynasty, and then takes root in regional Qinshu rap and local opera music, which takes root and thrives under the nourishment of immigrant culture.

In addition to the low and dark tone of traditional musical instruments, Gezai Opera absorbs the loud and bright dulcimer as the main accompaniment instrument. Its elegant appearance and lively and clear rhythm set off the horizontal performance of the East / West musical vocabulary, improved / new drama, single tone / harmony of the times. It just echoes the diversified development of immigrant culture and embraces all rivers, Lay the opportunity for Yangqin to be the main instrument in the backstage of Taiwanese Gezai Opera. 


\section{Mass media and the investment of musicians in the Pavilion}

With the invention of global industrial revolution, science and technology and the rise of new media in the 19th century, at the time of the transformation of Chinese and foreign culture and Western-style civilized society, the vigorous development of stage performance art. Influenced by mainland troupes, the completion and use of Danshui theater in 1909 led to the trend of troupes entering commercial theatres, followed by the establishment of modern theatres in the South and North, From the temple and wild high platform with the sound of mountains and forests and the noise of gongs and drums, Gezai Opera has entered the inner platform of the theater, which not only provides a place for public leisure and entertainment And gradually mature and prosperous; As for the transformation and transformation through the combination of mass media and transportation network, we can see from the following table that Taipei Beiguan children's music club set up Gezi Opera Troupes one after another at that time Table 1].

The corruption of the Qing Dynasty forced Taiwan to become a colony of the Japanese Empire under the "Treaty of Shimonoseki". The harsh power governance, the colonists forcibly implanted the new culture of Oriental culture, and the introduction of railways, theater buildings and mass media have been in full swing, eliminating, juxtaposing and influencing the life beliefs and entertainment activities followed in the immigrant culture.

In the early days of the Japanese occupation, in order to prevent the Anti Japanese behavior of the Taiwanese, Japan adopted a policy of tenderness and appeasement. The folk God worship flourished, and the exchange between theatrical troupes on both sides of the Strait was frequent. Under the strong pressure of colonial politics, it simulated the influence and impact of art and culture similar to that of the East and the West. At this time, Yangqin plays in folk orchestras and theatrical performances with the dual face of binary opposition, such as Chinese music / Western music, modern / conservative, difference / mixture, pavilion / theater, etc. ${ }^{7}$

In addition to preserving the phonemic arrangement of the Chinese traditional pentatonic scale, the "Yangqin", which is praised as "Yangqin" from the Great West, is rearranged and combined into two and a half octave arrangements in the Western minor scale introduced by the Japanese government and the simplified Chinese clef of Rome. With the help of science and technology and the transmission of the media, for the Class Pavilion The phonological arrangement of music clubs and folk music was reset so that it could appear in the music performance of the new culture movement in Taiwan as a "Chinese piano" with both accompaniment and main performance.

The infiltration of colonists was mainly cultural and ideological education. The turbulence and fierce transformation of Han culture are the only expedient methods that can be taken to continue the traditional culture in the construction of the artistic creation of Taiwan's new music "Minnan Ballads". At that time, popular Taiwanese operas such as Chen Sanwu Niang, Fuzhou strange case, wupen Ji and Shan boyingtai absorbed the performance methods from mainland theatrical troupes, integrated the front and back stages and organs, and entered the drama in folk minor and Nanguan minor in Southern Fujian, which became the melody captured by the creation of opera Ballads and created the music trend of emerging operas. ${ }^{8}$

$\mathrm{Su}$ Tong changed the folk minor "National Day tune" in Xiamen to the film theme song "Xuemei Sijun", which caused a sensation. Later, he successively launched "strange gentleman", "song of repentance" and "advocating a virtuous mother" Taiwanese films. Taiwanese ballads were put into the play, which not only expanded the value and dissemination of ballad art, but also absorbed the performance of Yangqin art, With the disintegration of the upper class of society and the rise of theater style mass comprehensive performing art, and the integration of primitive and multicultural, from the development of officials, gentry, merchants and a few musicians, as well as restaurants, theatres, pavilions and local music clubs, along with the improvement of printing technology and the prosperity of publishing industry, the distribution of newspapers and magazines, gramophones and turntables, films and production, With the rise of new entertainment undertakings such as theatres and dance halls, the dulcimer has been able to resist colonization and comply with the validity of obedience. In preserving the traditional culture and the oriental culture of colonists, it has adapted to the changes in the span of world affairs, and has become an indispensable instrument in the performance of eastern and Western bands.

At the end of 1948, Nanjing Kangjian Duma Opera Troupe introduced the improved "miscellaneous tune" of "Duma tune", which injected fresh blood into the Yangqin of Gezi Opera. Where there are five traditional tunes, namely "Duma tune", "seven character tune", "Jianghu tune", "zanian tune" and "crying tune", it is one of the important singing tunes ${ }^{9}$, highlighting the importance of the music accompaniment of the Yangqin of Gezi Opera.

\section{The vitality of the performing arts market and the position of dulcimer musicians}

After the separation of political barriers between the two sides of the Strait in 1949, urban and rural areas were built rapidly. In just a few years, Gezai Opera Troupes mushroomed in all parts of Taiwan. With the addition of actors and musicians from the mainland's "anti Jiandu MABAN Opera Troupe", the development of Yangqin in Gezai Opera Troupes was further strengthened. The total number of unregistered theatrical troupes in Taiwan is more than 385 . The lively temple fair celebrations and the festival of giving thanks to the gods have gradually formed a commercial theater ecology with a thriving performing arts market economy.

In the 1960s, Taiwan's economy gradually took off, and temple fairs kept moving around all over the place 
day and night. They became Taiwan's blessing and thanking God day and night. The Yangqin musicians of Gezi Opera were thirsty for talent. Not only did they work a few hours, but they were well paid. They could combine their expertise and interests, so they attracted many Yangqin musicians from folk halls and music clubs to join them.

With the assistance of senior musicians such as Su Tong, Xu Senyan, Liu sichong and Li Jianli, folk musical instrument factories produce a large number of self-made musical instruments, and the backcourt music talents of pavilions, music clubs have successively settled in commercial theatres. With the progress of television, radio, record and video technology, they even allied themselves with mass communication and electronic media network communication, and spread in Southeast Asia, as well as overseas Chinese communities such as the United States and Canada, You can hear the beautiful music of Gezai Opera accompanied by Yangqin. Zhou Di, a senior dulcimer, said:

When I was 19 years old, I was in the "Jiaxing society" Taiwanese Opera Troupe. Du Marin, the "Nanjing Du Ma ban" in Zhangzhou, taught me to play [Du Ma tune]. He said: "the seven character tune plays well with broad strings, but the Duma tune has a lot of overlapping words and is relatively free to sing. Because the rhythm is light, it needs a brighter voice to highlight the compactness of lyrics and melody. It is accompanied by dulcimer to have an atmosphere.

The backstage musicians of Taiwan theatrical troupes are elites from all over the world. In addition to being proficient and diverse in improvisation, they must also have the ability to organize members, arrange music, rehearse singing and composition. The internal foreman has the power to arrange personnel, dispatch musicians and distribute musical instruments. At the same time, we must know how to sing and accompany. Before there was no training in a special college, he did everything about backstage music on and off the stage. Unless he was responsive and smart, he couldn't be competent.

Therefore, Taiwan's Taiwanese Opera is in full swing. The performance day and night has attracted many musicians with better folk Pavilion skills to work in the backstage of Taiwanese opera. For example, Zhou Di, ye Mingde, Liu Yiwan, Martha, Li Dabao, Li Guozhi, Wei Xiangrong, etc. these musicians are outstanding Yangqin children from all the halls and clubs in Taiwan. Because they love Gezai Opera, most of them are the foremen of musicians in the civil and military arena after they join the troupe, which not only strengthens the Yangqin status of Gezai Opera, but also adds Jian Yongfu, an actor from the Ma troupe in Nanjing and a second-generation musician, It enriches Taiwan's unique opera accompaniment style.

Different from the four main instruments of Xiang opera, Yangqin has turned into the five main instruments accompanied by the backstage music of Taiwan's Gezai Opera.

\section{Cross strait exchanges and the gradual change of Yangqin}

1987 showed an unprecedented grand occasion. Just as the official Huang Deshi mentioned in the "credit investigation news" that the launch of TV Gezai Opera "has also played a role in the integration of people from other provinces and people from this province". Drama performance has the function of enlightening and infecting people to be good, and the function of inner reflection and eliminating all kinds of barriers. Gezai Opera and Xiang opera are based on the same "Chinese culture" soil. In recent years, the drama and cultural industry on both sides of the Strait has shown an overall trend of expanding the field of exchange and cooperation, continuously improving the level of exchange and cooperation, and increasingly improving the exchange and cooperation platform.

From the performances of the Heluo Taiwanese Opera scripts "killing the pig champion", "phoenix egg", "Swan banquet" and "singing on a good night", or even in the name of visiting relatives, field research, or visits by scholars, we can promote the opportunities of cross-strait cultural and artistic exchanges; In 1990, "minghuayuan Opera Troupe" participated in the 11th Beijing Asian Games Art Festival on behalf of Taiwan. Jian Yongfu became a dulcimer performer in Taiwan who officially landed on the mainland for the first time after the interruption of cross-strait exchanges; In 1993, the "one heart Gezai Opera Troupe" participated in the "cross-strait Gezai Opera Art Festival" on behalf of Taiwan. Yangqin musician Jian Yongfu and Gezai Opera artists went to Fujian to meet relatives and start the exchange between Gezai Opera and Xiang opera musicians.

With the exchange of Taiwanese Opera between the two sides of the Strait, by 1995, the "Zhangzhou Xiang Opera Troupe" performed in Taiwan, and Fujian scholars were invited to Taiwan to participate in the "academic seminar of Taiwanese Opera between the two sides". Chen Bin, the composer and arranger of Zhangzhou Xiang Opera Troupe, and Jiang Songming directed the cross-strait production group to jointly create the biography of Li WA, which truly opened the beginning of the "two-way exchange" of Yangqin art of Taiwanese Opera between the two sides of the Strait.

\section{The spread and improvement of Yangqin in Xiang Opera}

Taiwanese Gezai Opera Yangqin came to the Tzu Chi palace in Baijiao, Zhangzhou in 1928 with the sanlexuan class to perform incense. Due to the homology of sound and language, the melodies used are the songs of the 
original Minnan minor, which is very popular in Fujian cities. The folk Nanbei Opera Hall was changed into Gezai hall and gradually turned into a children's troupe to provide leisure and entertainment for ordinary people's life. During the Anti Japanese period, artists such as Wang Yinhe, Shao Jianghai and Lin Wenxiang absorbed nutrients from brocade songs, folk songs, folk songs, praise songs and some tunes of Chaozhou Opera, Gaojia opera and Beijing opera, improved them into new singing and accompaniment tunes, entered the opera as "improved opera", and re performed on the urban stage, which was deeply welcomed by the audience in Southern Fujian.

From the education and propaganda during the Anti Japanese War and calling on the people to "perform against the enemy" to the establishment of opera troupes after the Anti Japanese War, the improved and innovative singing art of Xiang opera has become more and more mature. After the victory of the war of resistance against Japan, Gezai Opera and reformed opera merged together and became a stream in Southern Fujian, which was loved by the public. After the founding of new China, the team of Gezai Opera and improved opera was re integrated. Because Gezai Opera was mainly popular in the Xiangjiang River Basin of Zhangzhou plain, it was named "Xiang opera". The history of using Yangqin in Xiang opera is very clear. The author interviewed Jiang Songhan, a member of the "bamboo shoot class" in Zhangzhou:

Brother likes playing musical instruments, so the elders of Chaozhou music club lent us Yangqin, huqin, Qin Qin and several other musical instruments. When I was 12 years old, a dulcimer elder named "Haocai" taught me and ah Haizi. We used it in turn for a week. My younger brother Jiang Songming likes playing musical instruments best. He can play Yangqin, Cello and huqin. So, at that time, there were three people in my family, plus other music friends. Going home every day was as lively as a concert. Later, the dulcimer broke down. In addition to the turmoil of the cultural revolution, my brother went to the art school. Later, he went to Zhangzhou Xiang opera troupe to play the dulcimer and violin. After adapting the tune and composing, there was less one main force.

The nature of music clubs and theatrical troupes is different. The former is the pleasure of musicians participating in the performance of music, regardless of their skills, and focuses on the cultivation of interpersonal relationships; The latter pays attention to the certification of professional skills and the amount of remuneration.

In 1960, under the trend of Fujian drama and music reform, the literary image and stage image of the old drama were moderately modified. The whole region changed the "screen system" to the script system, established the reserved repertoire system, and brought Xiang drama into the standardization of literary creation

The performance style of screen drama has been gradually "stereotyped";

For many reasons, such as the expansion of the orchestra's establishment, the increase of the types of musical instruments, the improvement of performance technology, the progress of composition technology, etc., with the gradual expansion of the backstage Orchestra, after symphonizing, it absorbed the twelve average law large variable dulcimer as the accompaniment instrument [Fig. 2];

The state-owned troupe was established, and the professional art school trained opera talents, creating a professional and competitive group. It is no longer the 12-year-old dulcimer in 1960 [figure 2] A pornographic play that was criticized by intellectuals in the past. While Taiwanese dulcimer musicians were still fighting for food and clothing for the north and South Temple Fairs, Xiang opera became the only public and most professional performing group on both sides of the Strait.

\section{Conflict and gradual change between traditional and modern dulcimer}

In 1987, the reform and opening up, the obstruction of the political situation in the half century, and the differences between the social structure and humanistic thoughts on both sides of the Strait operated and developed in their respective historical tracks. Across the Taiwan Strait, there were different survival contexts and music landscapes of Gezai Opera and Xiangju Yangqin on both sides of the Strait. Therefore, with the political lifting of the ban and the interconnection of cross-strait trade, art exchange has become the focus of cross-strait cultural connection, In 1989, the Department of traditional opera music of Taiwan experimental revival drama school (Department of traditional opera musicology of Taiwan opera academy) was established. Since then, it has moved towards the procedural training of professional opera talents. In addition, modern composers have made a lot of use of harmony, counterpoint and orchestration to change the polyphony of music. The traditional Yangqin has gradually been replaced by the improved large-scale twelve average Yangqin, It has not only changed the original Yangqin performance art of Gezi Opera, but also changed the performance procedure of the traditional backstage musician's impromptu rap with the actors.

The Gezi Opera Troupe employs composers to try to explore western composition, polyphony or atonality. It has never been in contact with opera and modern professional national orchestra to accompany opera. The traditional Yangqin seems to have lost its function of opera accompaniment. Most of the musicians in the troupe come from the training of the troupe apprenticeship system, lack of systematic training, and the music is relatively crude, In addition, Gezai Opera has always been known for its flexible use of accompaniment. The establishment of a small band of five or six people can complement each other's improvisation, flowers and instrument scheduling and conversion. If it is converted into a band of 60 people, it will be even more difficult to integrate the music.

In 1986, with the efforts of Xu Minggui's backcourt musician and Chen Zhongshen, Minghua garden 
successfully performed "Liu Quanjin melon" with the Taipei Municipal National Orchestra for the first time, which opened the situation that the traditional dulcimer and the large-scale twelve average dulcimer were performed on the same stage.

The traditional dulcimer accompanies the live singing part of Gezai Opera. The twelve average dulcimer is in a large orchestra and is responsible for the interlude of opening, closing and passing music. With the investment of cavity and composition talents, although the music is rich in color and the melody is beautiful and smooth, the traditional musician is still the soul of mastering the performance of the actors. The two seem to cooperate together, but in fact, they slowly weaken the function of traditional musicians in charge of stage actors in Gezai Opera. The importance of the traditional Yangqin of Taiwan's Gezai Opera to Mr. Qu Jiajiang Songming, a member of the Zhangzhou troupe who has cooperated with Taiwan for several times:

The timbre of the traditional two bridge dulcimer is very special and almost lost. Unexpectedly, Jian Yongfu of the Duma troupe played the Yangqin of Taiwanese Opera wonderfully, highlighting the different characteristics of Taiwanese Opera on both sides of the Strait. The traditional dulcimer of Taiwanese Gezai Opera and the large dulcimer of Xiang opera are two kinds of musical instruments under different ecology. The performance art of traditional dulcimer has been shaped into the "original" musical instrument ecology, aesthetic characteristics and musical art style of drama. The large dulcimer shows the integration of the band. Local operas must maintain their own style. The Yangqin of Gezi Opera and Xiang opera share the same root and the same origin, but there are differences in the same, and their respective development. This is a result of the development of backcourt musical instruments in Gezi Opera on both sides of the Strait after 60 years of separation. ${ }^{10}$

Under the exchanges between scholars, experts and non-governmental organizations on both sides of the Strait, Gezai Opera is engaged in cross-border, cross-cultural and even cross regional creation. Under the construction of the official professional and complete professional orchestra, the Yangqin musician of Xiang opera specially assigned a person to take charge of the drama working environment. According to the division of roles in the screenplay, he devoted himself to rehearsing and practicing according to Gong Yin Shang Lu.

The classic repertoire of wonderful Xiang opera, that is, in the stable working environment of the troupe, it is constantly refined and refined to build it into a national art performance project and promote the preservation plan of education and inheritance of traditional art talents. Taiwan's Gezai Opera, on the other hand, is still fighting for food and clothing for three meals, the north and South Temple Fairs, and is tired of running. Up to now, it is still in the state of competitive development of folk opera troupes. Due to the rich musical expression of Yangqin in the main and auxiliary operas, it has replaced the accompaniment function of plucked instruments, and Yangqin musicians are in short supply.

\section{Conclusion}

Looking back on the contemporary cross-strait Gezi Opera Yangqin exchange, it has gone through more than a year. During this period, it has gone through circuitous undercurrent, one-way sporadic, or even two-way dialogue and multi-dimensional hot contacts. It is by learning from the cross-strait cultural exchange and integration, the traditional culture is placed in the era of today's civilized society and adapted to the continuation and development of the evolution of the contemporary social environment Another form of evolution means the impact and development of "when tradition meets modernity".

Human beings try to maintain the survival of drama by continuous compensation and transformation. However, it is not inevitable whether they are handled properly. Do these remedial strategies form another negative breeding and catalysis? Like a virus, it has formed an environment that allows it to mutate, in order to explore various phenomena such as reference, impact and feedback after communication, and provide a more open, higherlevel and comprehensive communication channel and macro vision for the future by reviewing the history and looking forward to the future.

Entering the 21st century, Yangqin, as the art of performing traditional instrumental music in the backstage of Gezi Opera (Xiang Opera), disappeared with the death of musician Jian Yongfu in 2017 under the influence of modern cultural and artistic forms and popular fashion. In the face of the inheritance and survival challenges of traditional art, in the cultural environment of the global village and under the impulse of the multicultural environment, it is a problem that many traditional arts must think about in order to survive.

When "tradition meets modernity", choose to save or abandon it? Or it can still establish a performance of "instrument" and "person" in the "specific field". Through more bilateral exchanges and communication, crossstrait cultural inheritance and innovation, we must enhance cross-strait cultural and artistic exchanges and cooperation, work together for the Yangqin art of Gezi Opera (Xiang Opera), fuel and fire inheritance, light and light, go hand in hand across the Strait and move towards deeper development. 


\section{Appendix:}

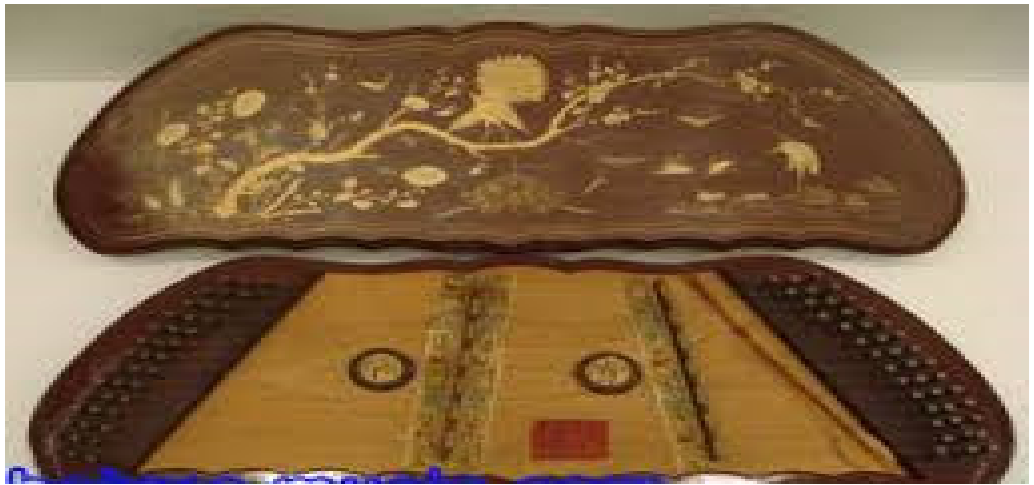

[figure 1] cited Taiwan Baile musical instrument company

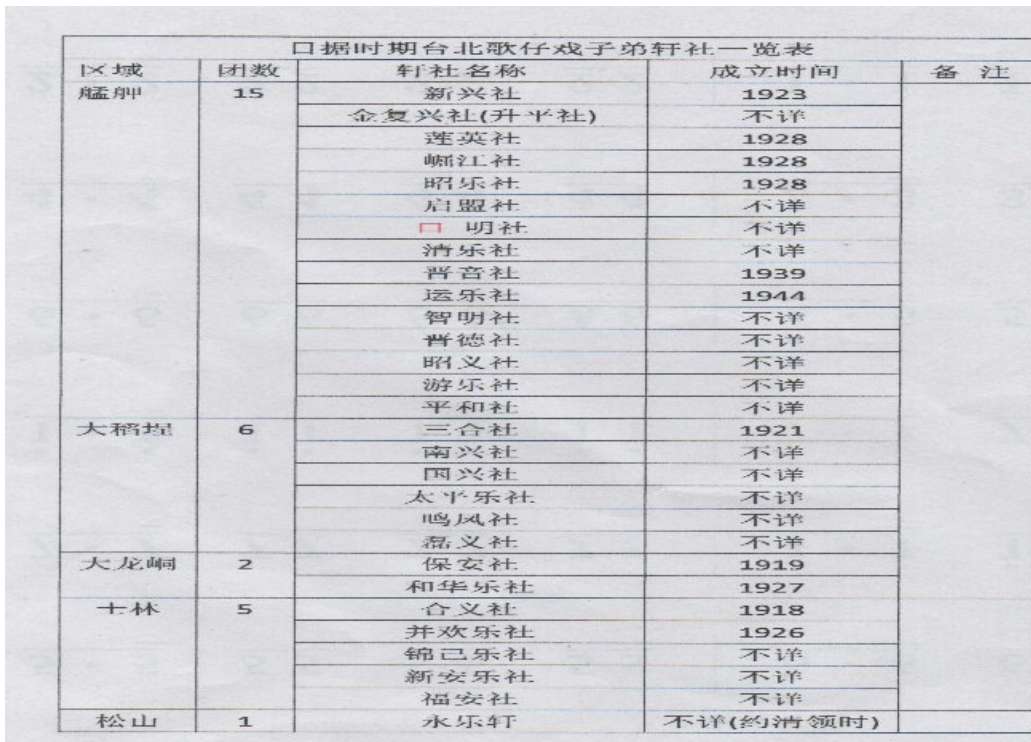

[table 1] northern Taiwanese Opera Troupe formation schedule

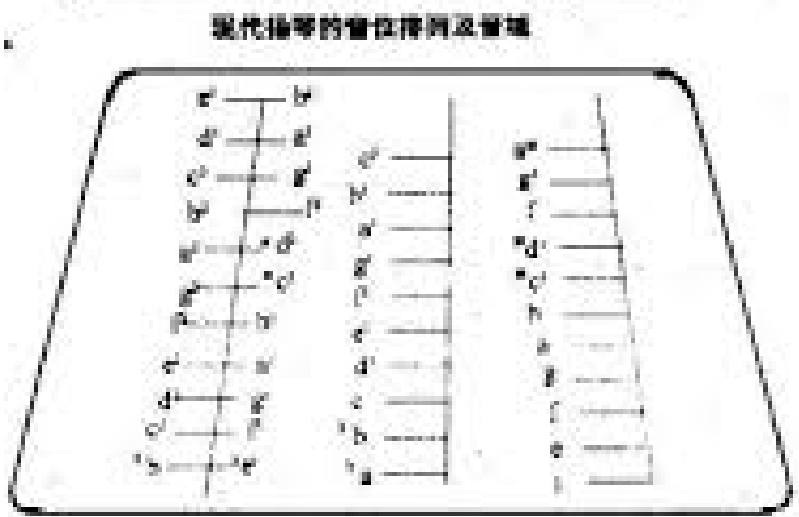

[figure 2] twelve flat dulcimer in 1960

\section{Bibliography}

1. Xu Yaxiang. Chinese theatrical troupes in Taiwan during the Japanese rule. Taipei: Nantian publishing house, 2008

2. Taipei municipal government. Development history of Taipei Beiguan Art —— Field records. Taipei: Taipei Municipal Bureau of culture, 2012

3. Lin Heyi and Cai Xinxin. Light and shadow. People. History: old photos of Gezi. Taiwan: Taiwan Traditional Art Center, 2013

4. Lin Heyi and Xu meihui. Quenching - Chen Yu's performance style and her era. Taipei: Taipei Municipal 
Bureau of culture, 2008

5. Lu v. Shang. History of Taiwan film. Taipei: Yinhua publishing house, 1961

6. Qiu kunliang. Old drama and new drama: a study of Taiwan Drama during the Japanese rule. Taipei: Zili evening news, 1992

7. Xu Yaxiang. Urban transformation Gezi flavor: the development history of Gezi Opera in Taipei. Taipei: Culture Bureau of Taipei municipal government, 2012

8. Du Xuezhi, Liao Hanchen. Tongzhi of Taiwan Province. Taiwan: Taiwan literature society, 1971

9. Field visit to Jian Yongfu, the second generation dulcimer musician of Duma class. 2008 / 12 / 24

10. Field visit to Jiang Songmin, composer of Zhangzhou Xiang Opera Troupe. October 1, 2019 